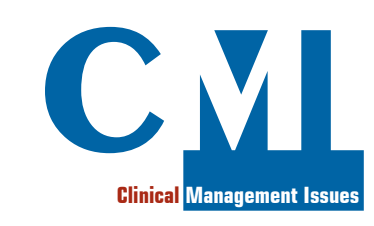

\title{
Editorial Staff Disclosure (2019)
}

Laura Fascio Pecetto is the Managing Editor of CMI journal. She does not have any personal conflict of interest to declare. She works at SEEd Medical Publishers, that in 2019 has worked with AdRes Srl, Aeroporti di Puglia S.p.A., Amgen Srl, Bayer Spa, Biogen Italia Srl, Boehringer Ingelheim Italia s.p.a., Bristol-Myers Squibb Srl, CD Pharma Group Srl, CREMS Srl, CSL Behring Spa, Fondazione Charta, Fondazione The Bridge, HPS-Health Publishing \& Services srl, Italfarmaco S.A., Janssen Cilag Spa, Mylan Italia Srl, Roche S.p.A.

Rossella Iannone is Editor of CMI journal. She does not have any personal conflict of interest to declare. She works at SEEd Medical Publishers, that in 2019 has worked with AdRes Srl, Aeroporti di Puglia S.p.A., Amgen Srl, Bayer Spa, Biogen Italia Srl, Boehringer Ingelheim Italia s.p.a., Bristol-Myers Squibb Srl, CD Pharma Group Srl, CREMS Srl, CSL Behring Spa, Fondazione Charta, Fondazione The Bridge, HPS-Health Publishing \& Services srl, Italfarmaco S.A., Janssen Cilag Spa, Mylan Italia Srl, Roche S.p.A.

Enzo Cappelluti is the Layout Editor of CMI journal. He does not have any personal conflict of interest to declare. He works at SEEd Medical Publishers, that in 2018 has worked with AdRes Srl, Aeroporti di Puglia S.p.A., Amgen Srl, Bayer Spa, Biogen Italia Srl, Boehringer Ingelheim Italia s.p.a., Bristol-Myers Squibb Srl, CD Pharma Group Srl, CREMS Srl, CSL Behring Spa, Fondazione Charta, Fondazione The Bridge, HPS-Health Publishing \& Services srl, Italfarmaco S.A.,Janssen Cilag Spa, Mylan Italia Srl, Roche S.p.A. 